\title{
Lung Cancer Management: where are we in 2017?
}

\author{
Giorgio Scagliotti, MD, $\mathrm{PhD}^{1}$, Paulo Bironzo, $\mathrm{MD}^{1}$ and Antoni Rosell, $\mathrm{PhD}^{2}$
}

${ }^{1}$ Department of Clinical and Biological Sciences, S. Luigi Gonzaga Hospital, University of Torino, Orbassano, Torino, Italy; ${ }^{2}$ Respiratory Medicine Department, Hospital Universitari de Bellvitge, Universitat de Barcelona, CIBERES, IDIBELL, Barcelona, Spain

\section{ABSTRACT}

Lung cancer remains the most common cancer and most common cause of death from cancer worldwide. Continuous advancements are taking place in this field. The year 2016 has brought many progresses; especially relevant are the new TNM Classification of Malignant Tumours (TNM) classification and the growing number of genomically-defined subpopulations in the road to developing personalized therapies. The state of the art in the management of lung cancer in 2016 is presented here. (BRN Rev. 2017;:267-85)

Corresponding author: Antoni Rosell, arosell@bellvitgehospital.cat

Key words: Bronchoscopy targeted chemotherapy. Immunotherapy. Lung cancer. Situation, Background, Assessment, Recommendation (SBAR). Screening thoracic surgery. 


\section{CONTROLLING RISK FACTORS FOR LUNG CANCER}

Data from the National Lung Screening Trial (NLST) showed a comparable survival benefit of smoking cessation and screening. However, other risk factors for lung cancer exist and their identification and regulation also play an important role in the burden of lung cancer. Particulate matter of 10 or less micrometres $\left(\mathrm{PM}_{10}\right)$ and fine particles $\left(\mathrm{PM}_{2.5}\right)$ have recently been associated with an increased risk of lung cancer, particularly adenocarcinoma, in a large European cohort ${ }^{2}$ and also in China, where the spatial variation of fine particles $\mathrm{PM}_{2.5}$ was correlated with an increase in lung cancer mortality ${ }^{3}$. The commitment of healthcare professionals to social awareness and patient advice as well as the engagement of healthcare organizations in the regulation of these and other environmental and occupational risk factors continuously updated by the International Agency for Research on Cancer is of utmost importance for controlling the burden of lung cancer worldwide.

\section{CANCER SCREENING}

Results from the NLST comparing low-dose computed tomography (LDCT) with chest X-ray showed a $20 \%$ reduction in mortality from lung cancer and a $6.7 \%$ reduction in death from any cause with LDCT screening, leading the US Preventive Services Taskforce to recommend annual LDCT screening for lung cancer in adults from 55 to 80 years-old who have a 30 pack-year smoking history and currently smoke or have quit within the last 15 years or if comorbidity develops that limits curative surgery or life expectancy ${ }^{4}$.

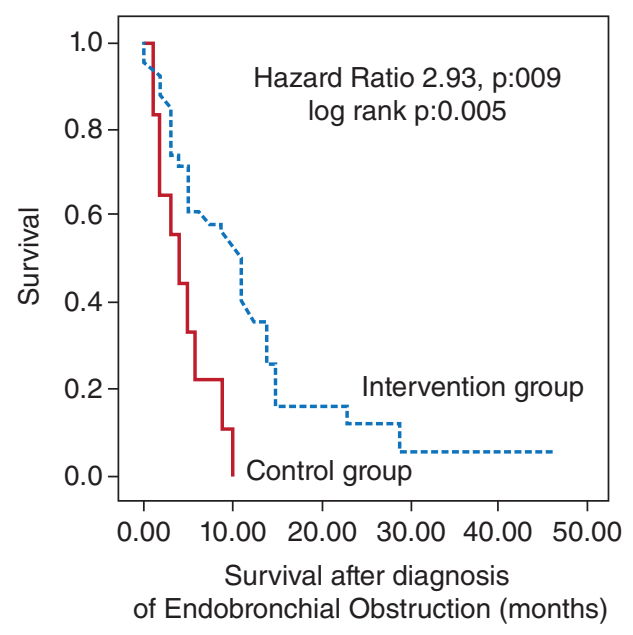

Figure 1. Kaplan Meier curves showing survival after diagnosis of airway obstruction in patients of the intervention group as compared to the control group (reproduced with permission from Stratakos $\mathrm{G}$ et al. ${ }^{19}$ ).

In Europe, several randomized controlled trials (RCT) have been conducted comparing LDCT with no screening. Like the NLST trial, Detection and Screening of Early Lung Cancer by Novel Imaging Technology and Molecular Assays (DANTE), Italian Lung cancer Computed Tomography screening trial (ITALUNG) and German Lung Cancer Screening Intervention Trial (LUCI) used a diameter-based protocol for nodule measurement; whereas Danish Lung Cancer Screening Trial (DLCST), UK Lung Cancer Screening (UKLS), Multicentric Italian Lung Detection study (MILD) and Dutch acronym for the Dutch-Belgian Randomized Lung Cancer Screening Trial (NELSON) used a volumetry-based (Fig. 1) protocol which has been shown to be superior $^{5}$. Previous European trials are too small to detect differences in mortality and therefore results on mortality reduction in this setting 
will need to be pooled with the upcoming results of the NELSON. Other questions such as the time lapse between rounds, radiologic criteria concerning nodule segmentation, as well as the management of the newly detected nodules during follow-up-which occurred in $5-7 \%$ of individuals at each round and proved to have a higher probability of malignancy in the NELSON trial- are still to be determined ${ }^{6,7}$. Furthermore, the application of risk models has proven to better identify the high-risk population that could benefit from screening, with improvements in both the effectiveness and the efficiency of the program ${ }^{8,9}$. In this sense, the addition of biomarker testing in different tissues such as airways epithelium, sputum and blood might further aid in identifying the target population. Cumulative data on non-coding RNAs suggests their involvement in lung cancer development and progression ${ }^{10-12}$. Future progress in this field, linked to the bioinformatic analysis of the growing number of reported microRNAs and long non-coding RNAs, could help better identify high-risk patients ${ }^{13}$. Finally, the availability of expert healthcare professionals to ensure not only adherence regarding selection and data collection but also to provide comprehensive smoking cessation counselling, adequate patient information and care when uncertainty is generated, as well as expertise in diagnosis and treatment when early lung cancer is detected, also determine the quality of a screening program ${ }^{14}$.

\section{DIAGNOSTIC AND THERAPEUTIC BRONCHOSCOPY}

In the endoscopy field, 2016 has provided different papers in which techniques expanding their usual anatomic limits to achieve a better diagnosis and staging of lung cancer were presented. Regarding treatments, novel procedures are being explored for peripheral lesions while more evidence is given for central airway obstruction recanalization.

\section{Diagnosis}

Transparenchymal nodule access (TPNA) is a new bronchoscopic technique that could be especially useful for those lesions smaller than $3 \mathrm{~cm}$ and without the bronchus sign (the visualization of a bronchial lumen reaching the nodule in the chest $\mathrm{CT}$ ). This technique differs completely from the established methods (radial endobronchial ultrasound [EBUS], Virtual Navigation, Electro Magnetic Navigation and ultrathin scopes), since it reaches the nodule via the lung parenchyma instead of taking a purely endobronchial path. Harzheim et al. ${ }^{15}$ present the first feasibility and safety study in an endoscopic unit. Six patients were recruited and a tunnel pathway (mean length $29 \mathrm{~mm}$ ) to the nodule was created in 5 patients. Two pneumothoraces were diagnosed by chest X-ray though only one required drainage. All samples were positive for this technique.

\section{Staging}

The meta-analysis in Korevaar et al ${ }^{82}$ demonstrates that the combined endoscopic ultrasound staging approach is definitively the best option for obtaining the broadest possible sampling of mediastinal lymph nodes. On average, the addition of transoesophageal endoscopic ultrasound (EUS) to EBUS increased sensitivity by 0.12 ( $95 \%$ confidence interval 
(CI): 0.08-0.18) and the addition of EBUS to EUS increased sensitivity by 0.22 (0.16-0.29). This combined approach achieves a mean sensitivity of 0.86 (0.81-0.90) and a mean negative predictive value of 0.92 (0.89-0.93).

EBUS can also obtain tissue samples from the left adrenal glands with a transgastric approach ${ }^{16}$, as well as with a transvascular approach, through the pulmonary artery and aorta ${ }^{17}$, with no complications.

\section{Treatment}

As the diagnostic yield of bronchoscopy improves with the incorporation of new endoscopic techniques, treatment options are also being considered. One of the latest is vapour ablation. In this pilot study in five healthy pigs, Henne et $\mathrm{al}^{18}$, demonstrated that a uniform field of necrosis following vapour administration into the subsegment of the anatomical boundary was achieved without major complications.

Although the interventional management of malignant central airway obstruction is well established, its impact on survival and quality of life (QoL) has not been studied extensively. Tumour debulking with any of the available methods (laser, electrocautery, cryoextraction...), and airway stabilization with stents when required (self-expandable metal or silicone), is the cornerstone of the treatment of critical airway stenosis. As a RCT with or without endoscopic treatment is unethical in this group of patients, any evidence is well appreciated. Stratakos et al. ${ }^{19}$ have managed to prospectively compare survival, QoL and dyspnoea in a small group of 34 patients with non small cell lung cancer (NSCLC) that underwent extensive interventional bronchoscopic procedures and 12 that declined. Both groups were comparable in tumour, node, metastasis (TNM) stage, Eastern Cooperative Oncology Group (ECOG) score and level of airway obstruction. Bronchoscopic treatment was totally or partially successful in $91.2 \%$ of them. Mean survival time for the intervention group and control group was $10 \pm 9$ and $4 \pm 3$ months, respectively $(\log$ rank $\mathrm{p}=0.005)$. The death hazard ratio (HR) increased 2.93 times without interventional management $(\mathrm{p}=0.009)$ (Fig. 2). This report confirms that multimodality treatment is necessary for patients with central tumours.

\section{THE NEW TNM}

One of the main articles published in 2016 refers to the new nomenclature for tumour stage classification promoted by the International Association for the Study of Lung Cancer $\left(\right.$ IASLC) ${ }^{20}$.

The new TNM is based on a new global database of 94,708 patients from 16 countries diagnosed between 1999 and 2010. External validation was demonstrated using the US-based National Cancer Database. This classification of lung cancer is the worldwide standard as of January 1, 2017.

In short, the differences with respect to the previous edition are as follows: $\mathrm{T}$ categories have been broken down further by size (in $1 \mathrm{~cm}$ increments up to $5 \mathrm{~cm}$ ). Tumours that are $>5-7 \mathrm{~cm}$ are now T3 and T4 if $>7 \mathrm{~cm}$. Central tumours involving a main bronchus or causing obstructive atelectasis are all classified as T2a regardless of the distance to the carina or whether the lung is partially or completely 


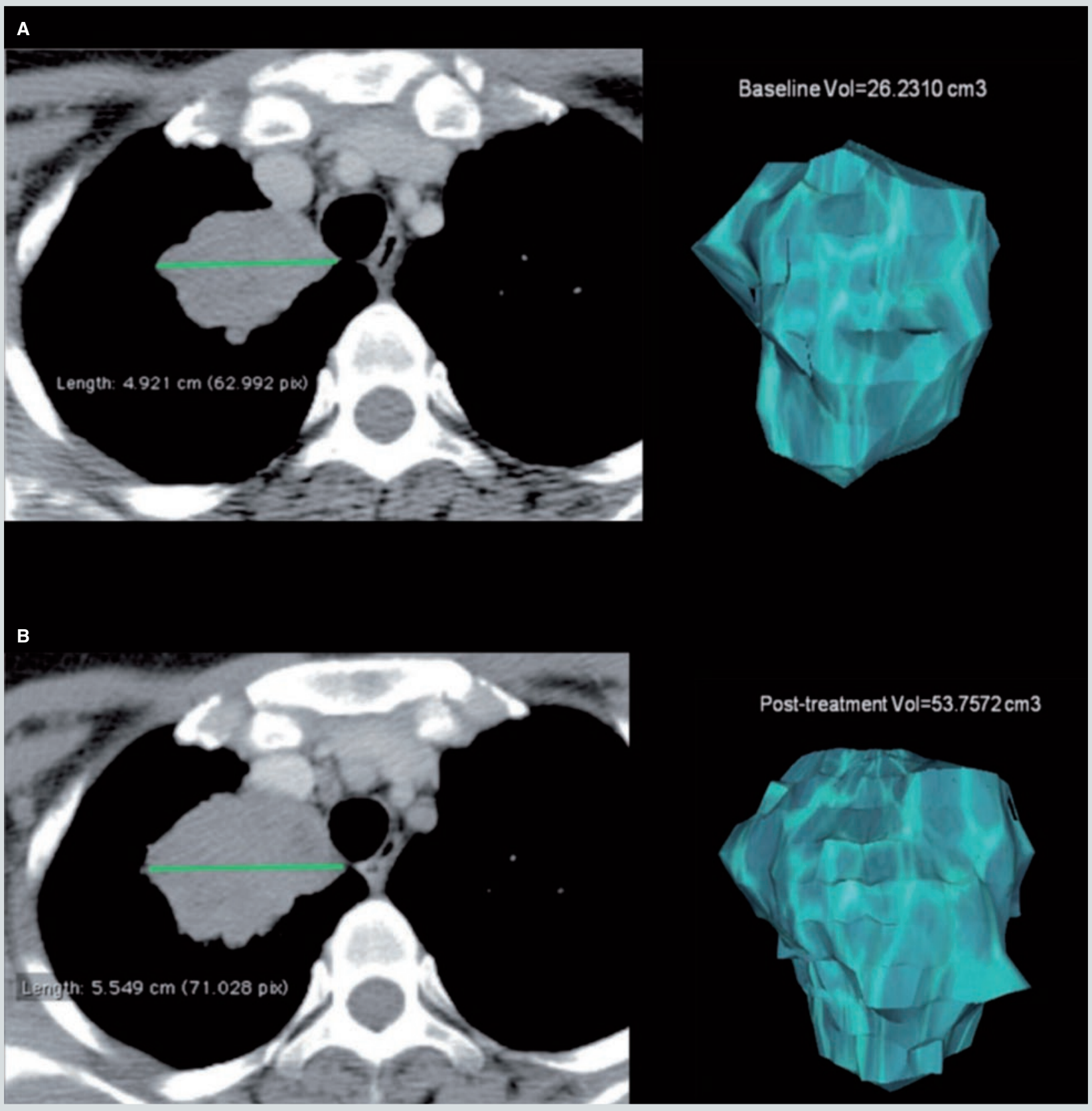

Figure 2. Volumetric assessment of a lung mass. A: Computed tomography (CT) and segmented volume at baseline. B: CT and segmented volume after treatment. From A to B maximum diameter has increased $0.63 \mathrm{~cm}$ whilst volume has doubled (reproduced with permission from Bernardin L. et al.83).

atelectatic. Tumours involving the diaphragms are classified as T4. There are no changes in the $\mathrm{N}$ categories. The $\mathrm{M}$ category now distinguishes tumours with a solitary distant metastasis from multiple metastases (Tables 1 and 2).
With regard to the $\mathrm{T}$ component, the way that its size should be measured is specifically addressed. The maximum dimension of the solid component or the invasive component is used to assign the $\mathrm{T}$ category. 
TABLE 1. Surgery for lung cancer 30 -days mortality risk score

\begin{tabular}{|l|l|}
\hline Risk score & \\
\hline ppo $\mathrm{FEV}_{1} \%$ & \\
\hline Coronary artery disease & 1 point \\
\hline Extensive resection & \\
\hline Age $>65$ years & 2 points \\
\hline Cerebrovascular disease & \\
\hline Male & \\
\hline Thoracotomy & 3 points \\
\hline BMI < 18.5 & \\
\hline Pneumonectomy & \\
\hline 30 day mortality rates by Eurolung (1) aggregate score \\
\hline $0-3$ points & $0.4 \%$ \\
\hline $4-6$ points & $1.4 \%$ \\
\hline $7-8$ points & $2.9 \%$ \\
\hline $9-11$ points & $5.2 \%$ \\
\hline $12-14$ points & $11.3 \%$ \\
\hline $15-29$ points & $29.4 \%$ \\
\hline
\end{tabular}

BMI: body mass index; $\mathrm{FEV}_{1} \%$ : forced expiratory volume in the first second; ppo: predicted post-operative.

However, the maximum dimension of the ground glass or lepidic component should also be recorded. It is worth highlighting that when multiple $\mathrm{T}$ descriptors are applicable to a tumour, the highest $\mathrm{T}$ category should be chosen.

\section{SURGERY}

\section{Survival}

Strong evidence published this year reinforces the known variables associated with better outcomes for patients undergoing surgery. Patient selection, a hospital's surgical volume and the tumour board's adherence to guidelines are among them.
TABle 2. Definitions for the Tumor, node, metastasis (TNM) descriptors

\begin{tabular}{|c|c|c|}
\hline \multicolumn{2}{|c|}{$\mathrm{T}$ (primary tumour) } & \multirow[t]{2}{*}{ Label } \\
\hline TO & No primary tumour & \\
\hline Tis & $\begin{array}{l}\text { Carcinoma in situ (squameous } \\
\text { or adenocarcinoma) }\end{array}$ & $\mathrm{T}$ is \\
\hline $\mathrm{T} 1$ & Tumour $\leq 3 \mathrm{~cm}$ & \\
\hline T1a (mi) & Minimally invasive adenocarcinoma & T1a (mi) \\
\hline T1a & $\begin{array}{l}\text { Superficial spreading tumour in } \\
\text { central airways }\end{array}$ & T1a SS \\
\hline T1a & Tumour $\leq 1 \mathrm{~cm}$ & $\mathrm{~T} 1 \mathrm{a} \leq 1$ \\
\hline $\mathrm{T} 1 \mathrm{~b}$ & Tumour $>1$ but $\leq 2 \mathrm{~cm}$ & $\mathrm{~T} 1 \mathrm{~b}>1-2$ \\
\hline T1c & Tumour $>2$ but $\leq 3 \mathrm{~cm}$ & $\mathrm{~T} 1 \mathrm{c}>2-3$ \\
\hline \multirow[t]{3}{*}{ T2 } & $\begin{array}{l}\text { Tumour }>\text { but } \leq 5 \mathrm{~cm} \text { or tumour } \\
\text { involving: }\end{array}$ & \\
\hline & Visceral pleura & $\mathrm{T} 2$ visc $p l$ \\
\hline & $\begin{array}{l}\text { Main bronchus, atelectasis } \\
\text { to hilium }\end{array}$ & T2 centr \\
\hline T2a & Tumour $>3$ but $\leq 4 \mathrm{~cm}$ & $\mathrm{~T} 2 \mathrm{a}>3-4$ \\
\hline $\mathrm{T} 2 \mathrm{~b}$ & Tumour $>4$ but $5 \mathrm{~cm}$ & $\mathrm{~T} 2 \mathrm{~b}>4-5$ \\
\hline \multirow[t]{3}{*}{$\mathrm{T} 3$} & Tumour $>5$ but $\leq 7 \mathrm{~cm}$ & $\mathrm{~T} 3>5-7$ \\
\hline & $\begin{array}{l}\text { or invading chest wall, } \\
\text { pericardium, phrenic nerve }\end{array}$ & T3 inv \\
\hline & $\begin{array}{l}\text { or separate tumour nodule (s) } \\
\text { in the same lobe }\end{array}$ & T3 satell \\
\hline \multirow[t]{3}{*}{$\mathrm{T} 4$} & Tumour $>7 \mathrm{~cm}$ & $\mathrm{~T} 4>7$ \\
\hline & $\begin{array}{l}\text { or tumour invading: mediastinum, } \\
\text { diaphragm, heart, great vessels, } \\
\text { recurrent laryngeal nerve, carina, } \\
\text { trachea, esophagus, spine }\end{array}$ & T4 inv \\
\hline & $\begin{array}{l}\text { or tumour nodule(s) in a different } \\
\text { ipsilateral nodule }\end{array}$ & T4 ipsi nod \\
\hline \multicolumn{3}{|c|}{ N (regional lymph nodes) } \\
\hline No & No regional node metastasis & \\
\hline N1 & $\begin{array}{l}\text { Metastasis in ipsilateral pulmonary } \\
\text { or hiliar nodes }\end{array}$ & \\
\hline N2 & $\begin{array}{l}\text { Metastasis in ipsilateral mediasti- } \\
\text { nal/subcarinal nodes }\end{array}$ & \\
\hline N3 & $\begin{array}{l}\text { Metastasis in contralateral medias- } \\
\text { tinal/hiliar, or supraclavicular nodes }\end{array}$ & \\
\hline \multicolumn{3}{|c|}{ M (distant metastasis) } \\
\hline Mo & No distant metastasis & \\
\hline M1a & $\begin{array}{l}\text { Malignant pleural/pericardial effusion } \\
\text { or pleural/pericardial nodule } \\
\text { or separate tumour nodule(s) in a } \\
\text { contralateral lobe }\end{array}$ & $\begin{array}{l}\text { M1a pl dissem } \\
\text { M1a contr nod }\end{array}$ \\
\hline M1b & Single extrathoracic metastasis & M1b single \\
\hline M1c & $\begin{array}{l}\text { Multiple extrathoracic metastasis } \\
\text { (1 or }>1 \text { organ) }\end{array}$ & M1c multi \\
\hline
\end{tabular}

Reproduced with permission from Detterbeck FC et al. ${ }^{20}$. 
TABLE 3. Lung cancer stage grouping

\begin{tabular}{|c|c|c|c|c|c|}
\hline $\mathrm{T} / \mathrm{M}$ & Label & NO & N1 & N2 & N3 \\
\hline \multirow[t]{3}{*}{ T1 } & $\mathrm{T} 1 \mathrm{a} \leq 1$ & IA 1 & \multirow{6}{*}{ II B } & \multirow[t]{6}{*}{ III A } & \multirow[t]{6}{*}{ III B } \\
\hline & $\mathrm{T} 1 \mathrm{~b}>1-1$ & IA 2 & & & \\
\hline & $\mathrm{T} 1 \mathrm{c}>2-3$ & IA 3 & & & \\
\hline \multirow[t]{3}{*}{$\mathrm{T} 2$} & T2a centr visc $p /$ & \multirow[t]{2}{*}{ I B } & & & \\
\hline & $\mathrm{T} 2 \mathrm{a}>3-4$ & & & & \\
\hline & $\mathrm{T} 2 \mathrm{~b}>4-5$ & II A & & & \\
\hline \multirow[t]{3}{*}{ T3 } & $\mathrm{T} 3>5-7$ & \multirow[t]{3}{*}{ II B } & \multirow[t]{3}{*}{ III A } & \multirow[t]{6}{*}{ III B } & \multirow[t]{6}{*}{ III C } \\
\hline & T3 inv & & & & \\
\hline & T3 satell & & & & \\
\hline \multirow[t]{3}{*}{ T4 } & $\mathrm{T} 4>7$ & \multirow[t]{3}{*}{ III A } & & & \\
\hline & T4 inv & & & & \\
\hline & T4 satell & & & & \\
\hline \multirow[t]{4}{*}{ M1 } & M1a centr nod & \multicolumn{4}{|l|}{ IV A } \\
\hline & M1a pl dissem & & & & \\
\hline & M1b single & & & & \\
\hline & M1c multi & IV B & & & \\
\hline
\end{tabular}

T: tumour; M: metastasis; N: node.

Reproduced with permission from Detterbeck FC et al. ${ }^{20}$.

A large pool of subjects from the European Society of Thoracic Society (ESTS) database (2007-2015) was used to build risk models for morbidity (EuroLung1) and mortality (EuroLung2). An aggregate score was created that stratified the patients into six classes of incremental mortality risk $(\text { Table } 3)^{21}$.

Some of these variables, such as pulmonary function, can be modified before surgery. The systematic review and metaanalysis performed by Sebio et al. ${ }^{22}$, demonstrated that FVC and $\mathrm{FEV}_{1}$ were significantly enhanced following preoperative exercise training. In comparison with the patients in the control groups, patients in the experimental groups spent fewer days in hospital (mean difference $=-4.83 ; 95 \% \mathrm{CI}$ : $-5.9,-3.76)$ and had fewer postoperative complications (risk ratios $=0.45 ; 95 \% \mathrm{CI}$ : $0.28,0.74)$.

Other variables do not depend on patient selection, but on the centre's activity and on the tumour board's adherence to guidelines. A study by Moller et al. ${ }^{23}$ grouped hospitals in England into quintiles: the first group performed 1 to 75 resections each year, while the fifth quintile performed 189 to 287 . This cohort analysis demonstrates that hospitals with large resection volumes admitted older, more comorbid and poor performance status patients and had a likelihood of readmission around 15\% lower and about half the likelihood of death within 30 days than patients in the lowest quintile hospitals. This gives support to the ongoing trend towards the centralization of clinical services, though referral routes and patient access must also be taken into account. Tumour board adherence to quality measures in lung cancer guidelines was low in a large retrospective study of patients with clinical stage I NSCLC in the United, based on the Nation Cancer Database ${ }^{24}$. Four quality measures were selected from the guidelines: anatomic resection, operation within 8 weeks of diagnosis, achievement of negative surgical margins, and sampling of 10 or more lymph nodes. Only 30,041 patients out of $133,366(22.5 \%)$ met all four measures. The HR for overall survival for these patients was significantly different from those meeting 1 criteria (HR: 0.70 ; 95\% CI: 0.56-0.88) and those meeting 4 criteria (HR: 0.39 ; 95\% CI: 0.31-0.48). As guideline compliance is strongly associated with survival, other bodies, apart from national societies, should be involved to improve adherence. 


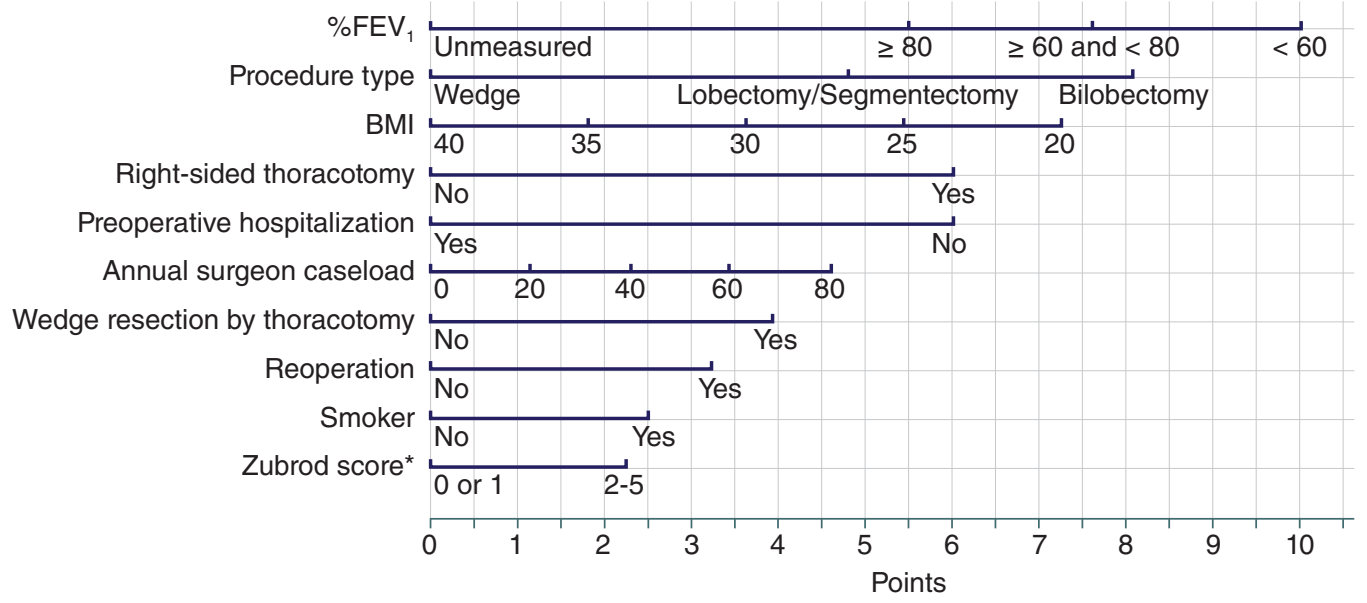

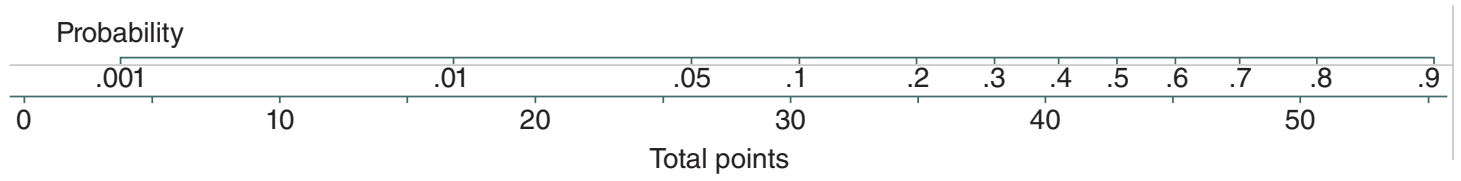

Figure 3. Normogram to calculate the probability of prolonged air leak (reproduced with permission from Attaar $A$ et al. ${ }^{25}$ ).

* Zubrod score corresponds to the rating of quality of life of the Group of Eastern Cooperative Oncology (ECOG) in cancer patients, also known as performance status (PS). Http://ecog-acrin.org/resources/ecog-performance-status.

BMI: body mass index. $\mathrm{FEV}_{1}$ : forced expiratory volume in the first second.

\section{Air leak}

Attaar et al. $^{25}$ have described a clinical prediction model for prolonged parenchymal air leaks ( $>5$ days) after pulmonary resection (Fig. 3). Each variable was associated to a score and patients were then stratified into three risk groups with a monotonic increase: low ( $\leq 25$ points), intermediate (26-29) and high ( $\geq 30$ ) risk groups, with an incidence of 2.0, 8.9 and $19.2 \%$, respectively.

\section{Patient-centred outcomes}

The first step towards patient-centred outcomes has been already taken with the publication of the International Consortium for Health
Outcomes Measurement. Through a modified Delphi method, Mak et al. ${ }^{26}$ defined an international consensus recommendation of the most important outcomes for lung cancer patients, including time from diagnosis to treatment, acute and major complications of treatment, quality of life, survival and cause of death and finally, quality of death (duration of time spent in hospital at end of life, and where patient died). This set of recommendations must now be validated and implemented in a pilot study.

\section{Robots}

Publications on robotic surgery have accumulated in the last decade. However, controversy remains about the application of robotic surgery, 
together with a lack of well-established evidence. Louie et $a .^{27}$ have published a comparative study based on the Society of Thoracic Surgeons Database in the United States of America for clinical Stage I and II NSCLC. Robotic lobectomies were longer (median 186 versus 173 minutes; $p<0.001$ ) but more patients had hospital stays of less than 4 days (48 versus $39 \%$; $<<0.001)$. The rest of intra-operative measurements and all post-operative outcomes were similar. Thus, based on this retrospective comparative study, it seems that robotic surgery is equal, but not clinically superior to video-assisted thoracic surgery (VATS).

\section{PHARMACOLOGICAL TREATMENTS}

\section{Early stages}

In order to shift treatment paradigms from the advanced to the adjuvant setting, biologic agents have also been investigated in radically resected patients, without achieving any advantage for bevacizumab and erlotinib in unselected populations. However, an improvement in disease-free survival (DFS) was observed with erlotinib in epidermal growth factor receptor (EGFR) mutation positive patients (without reaching statistical significance), paving the way for currently ongoing trials testing EGFR-tyrosine kinase inhibitors (TKIs) in resected patients [NCT01405079, NCT01996098, NCT02125240] $]^{28}$.

Aiming at treatment personalization, results from an Italian phase III randomized adjuvant customized chemotherapy trail [ITACA] exploring putative predictors of chemotherapy sensitivity or resistance are eagerly awaited.
Another intriguing strategy in the adjuvant setting exploits the potential of harnessing the immune system to achieve a complete clearance of residual tumour cells. In this context, a large phase III vaccination trial in stage IB-IIIA resected patients expressing melanoma-associated antigen 3 (MAGE-A3) failed to improve $\mathrm{DFS}^{29}$. Immune checkpoint inhibitors are currently also being tested in resected patients, following the results obtained in the advanced setting [NCT02486718, NCT02273375, NCT02504372].

In order to maximize treatment personalization in completely resected NSCLC patients, the U.S. National Clinical Trial Network is currently conducting a prospective multi-arm adjuvant trial [ALCHEMIST - NCT02201992, NCT02193282, NCT02194738] in which treatment allocation is based on the genomic features of each tumour. After completing standard adjuvant treatment, patients are randomized, based on the presence of anaplastic lymphoma kinase (ALK) rearrangements, EGFR mutations or the absence of both, to either placebo or crizotinib, erlotinib or nivolumab, respectively. Moreover, tumour genomics will be studied in greater depth in order to find any new predictive and prognostic factors that may emerge.

For the vast majority of Stage III NSCLC patients, standard therapy requires a multimodality therapeutic approach. Unresectable disease should preferentially be treated with concomitant chemo-radiotherapy (cCTRT), the most commonly used regimen being cisplatin with etoposide. Randomized trials testing modern platinum-based doublets, such as cisplatin plus pemetrexed and cisplatin plus vinorelbine, have failed to demonstrate superiority over that doublet, even though the toxicity profile appeared to be better with new agents ${ }^{30,31}$. 
Several ongoing studies are exploring molecular targeted agents in locally advanced NSCLC [NCT01822496, NCT02412371, NCT01386385], as well as immune checkpoint inhibitors [NCT02125461]. A major information breakthrough in this field was reported at the European Society of Medical Oncology (ESMO) meeting in September 2016. A small study presented by Forde et al. ${ }^{32}$ reported 7 pathologic responses with less than $10 \%$ of tumour viable cells among 18 patients with resectable NSCLC treated with 2 cycles of neoadjuvant nivolumab therapy. When confirmed in a larger population, these data could open the door to a new series of studies in locally advanced NSCLC.

\section{Advanced NSCLC treatment}

In the last decade, the evidence that histology should guide the treatment decision making process, followed by the introduction of targeted agents for specific lung cancer populations harboring abnormally activated oncogenic introduced a personalized approach into lung cancer treatment. More recently, emerging knowledge about some of the mechanisms that govern the complex interaction between tumour cells and the host immune system, prompted a re-discovery of immune-oncology in lung cancer treatment, as well as in other tumours ${ }^{33}$.

\section{Oncogene-driven NSCLC}

\section{EGFR MUTATED NSCLC}

First-line treatment of patients with advanced EGFR-mutation positive NSCLC is based on TKIs. A randomized phase II trial comparing a first- versus a second-generation EGFR TKI (gefitinib and afatinib, respectively) in this setting failed to demonstrate any difference in OS between the two drugs, even though afatinib treatment increased both progression-free survival (PFS) and time to treatment failure $(\mathrm{TTF})^{34,35}$. As of today, the agent of choice for first-line treatment in EGFR mutated patients is mainly based on the physician's expertise with different molecules and their different toxicity profiles.

Turning now to second-line treatments, since approximately $50 \%$ of patients develop resistance to first- and second-generation TKIs through a specific secondary EGFR mutation, T790M targeted agents have been developed in order to overcome this mechanism. Among them, osimertinib (previously known as AZD9291) represents the current standard of care in advanced EGFR-mutated T790M-positive NSCLC patients who progressed to first-line EGFR TKIs after the results of an AURA 3 randomized phase III trial ${ }^{36}$. This study randomized 419 T790M-positive (as assessed on tumour biopsy) to receive either osimertinib $80 \mathrm{mg}$ once daily or platinum (cisplatin or carboplatin) plus pemetrexed chemotherapy. Osimertinib significantly prolonged PFS as compared to chemotherapy (10.1 versus 4.4 months; HR: 0.30; 95\% CI: 0.23-0.41; p < 0.001); moreover, osimertinib treatment significantly enhanced the objective response rate (ORR) (71 versus $31 \%$; odds ratio 5.39; 95\% CI: 3.47-8.48; p < 0.001) and results in less G3 and 4 adverse events (AEs) (23 versus $47 \%$ ). In the light of these results, obtaining a second biopsy as the disease progresses seems to be crucial. However, this can prove difficult due to the location of the progressing site or to patient's performance status. 
The introduction of a so-called "liquid biopsy" represented a turning point in this clinical scenario and, even though a standardized method for the detection of EGFR mutations in plasma is currently lacking, results from ancillary studies in patients treated with third-generation EGFR TKIs report a sensitivity of between 51 and $70 \%$, depending on the assay, and a specificity of approximately $77 \%{ }^{37-39}$. Taken all together, these data suggest the reliability of plasma genotyping in this patient population, especially when a positive result is found. In contrast, in patients with a negative plasma result, a tissue biopsy is mandatory before considering them to be "truly" negative.

\section{ALK-REARRANGed NSCLC}

ALK-rearrangements are detected in approximately 5\% of NSCLC. Along with crizotinib, the first targeted agent approved for the treatment of this lung cancer population, in recent years many other ALK inhibitors have entered into clinical trials. Many of them are characterized by a higher penetration in the central nervous system (CNS) than their progenitor, and some of them are active against secondary ALK mutations leading to crizotinib resistance.

Alectinib is a second-generation ALK TKI that demonstrated activity in both crizotinib-naive and pretreated patients in phase II trials ${ }^{40}$. Results from a phase III randomized trial of alectinib versus crizotinib in Asian ALK-inhibitors naive advanced ALK-positive NSCLC patients demonstrated an impressive alectinib activity in terms of objective RR as compared to crizotinib (ORR by independent review 91.6 versus $78.9 \%$ ) with a median PFS not reached versus 10.2 months in the experimental and control arm, respectively (HR: $0.34,95 \% \mathrm{CI}$ : $0.17-0.71 ; \mathrm{p}<0.0001)^{41}$. Results from a twin study conducted in caucasians are awaited soon.

Another second-generation ALK inhibitor, ceritinib, which is already registered by the U.S. Food and Drug Administration (FDA) for patients progressing or intolerable to crizotinib, proved to be superior to platinum plus pemetrexed chemotherapy in previously untreated ALK-rearranged NSCLC, increasing median PFS by over 8 months (16.6 versus 8.1 months; HR: $0.55,95 \%$ CI: $0.42-0.73 ; \mathrm{p}<0.001)$ in a phase III trial $^{42}$.

The same agent proved to significantly increase mPFS as compared to single-agent chemotherapy in ALK-rearranged advanced NSCLC patients previously treated with chemotherapy and crizotinib (5.4 versus 1.6 months; HR: 0.49; 95\% CI: 0.36-0.67; p < 0.001). In this phase III trial, ceritinib treatment led to a higher $R R$ and disease control rate (DCR) and a significant improvement in lung cancer symptoms and overall health status ${ }^{43}$.

Two other ALK inhibitors (brigatinib and lorlatinib) showed promising activity in crizotinib pre-treated ALK-rearranged patients and one of them, brigatinib, received a breakthrough therapy designation by the FDA in October 2014 for crizotinib-resistant ALK-rearranged NSCLC $^{44,45}$. Of note, both agents are highly active even in patients with CNS disease.

Unlike EGFR-mutated disease, crizotinib resistance mechanisms are extremely heterogeneous as there is no single dominant secondary mutation such as T790M. Importantly, different new generation agents seem to be active against specific mutations, possibly leading in the near future to a tailored approach based on each 
patient's emergent secondary mutations ${ }^{46}$. In order to do this, liquid biopsies are currently being investigated in ALK-positive patients with some interesting preliminary reports ${ }^{47}$.

\section{OTHER ONCOGENE-DRIVEN NSCLCS}

Besides EGFR and ALK, many other genes are emerging as potential targets in NSCLC treatment. Among them, ROS1 rearrangement already has its own FDA-approved targeted agent, crizotinib ${ }^{48}$ following the results of an expansion cohort of a Profile 1001 trial in which ROS1-positive patients achieved a 72\% response rate with a median duration of response of 17.6 months ${ }^{49}$. Even if this alteration is rare, accounting for approximately $2 \%$ of NSCLC, many ongoing studies are testing new inhibitors in this specific subgroup of patients and even here resistance mechanisms, such as the G2032R mutation, are increasingly being reported ${ }^{50}$.

Rearranged during transfection (RET) gene fusions have been reported in $1 \%$ of NSCLC, especially in adenocarcinomas, the most common partner gene being KIF5B, which accounts for $90 \%$ of cases ${ }^{51}$. Ongoing studies are evaluating different targeted agents (cabozantinib, vandetanib, lenvatinib, apatinib, ponatinib, RXDX-105) in this lung cancer subgroup. However responses seem to be much lower when compared to other oncogene-addicted NSCLC populations ${ }^{52-54}$. Neurotrophic tyrosine kinase (NTRK)-1 oncogenic fusions have been reported in 3.3\% of lung adenocarcinomas that were negative for other common driver mutations and several trials with specific inhibitors are ongoing. One of these agents, entrectinib, was granted FDA Orphan
Drug designation for the treatment of Tropomyosin kinase (Trk)A, TrkB-, and Trk-C-positive NSCLC and colorectal cancer patients ${ }^{54}$. c-MET is a receptor-tyrosine kinase whose aberrant activation in lung cancer could be due to MET gene amplification $(2-4 \%)^{55}$ or exon 14 skipping mutations (3-4\%) ${ }^{56}$. Gene amplification could also mediate secondary resistance in up to $20 \%$ of EGFR-mutated NSCLC patients treated with EGFR TKIs, as well as some ALK-rearranged ones.

Early results from phase II of a phase IB/II study exploring double inhibition with an EGFR TKI and captmatinib, a selective c-MET inhibitor, in MET-amplified EGFR-mutated NSCLC progressing to first-line EGFR TKI, showed a promising $80 \% \mathrm{DCR}^{57}$. Additionally, capatinib, as well as other MET inhibitors, are currently being investigated in patients with MET exon 14 mutations (for review see reference ${ }^{50}$ ).

Kirsten rat sarcoma (KRAS) mutations occur in up to $25 \%$ of lung adenocarcinomas, mainly involving codons 12 and 13. These mutations are usually mutually exclusive with ALK and EGFR alterations and frequently associated with smoking habits. Selumetinib is an orally available inhibitor of MAPK/Erk kinase (MEK), a downstream molecule in the KRAS activating pathway and proved to significantly increase both ORR and PFS in a randomized phase II trial in KRAS-mutated advanced NSCLC, when given in association with docetaxel. However, a phase III trial failed to show any survival benefit by adding selumetinib to docetaxel in this population ${ }^{58}$.

Activating the human gen BRAF mutations, mainly V600E, are found in 1 to $4 \%$ of NSCLC, 
especially in current or former smokers. While single-agent BRAF inhibitor strategies achieved only limited benefits with an ORR between 33 and $42 \% 59,60$, a phase II trial of BRAF and MEK double inhibition with dabrafenib plus trametinib in BRAF(V600E)-mutated advanced NSCLC after failure of platinum-based chemotherapy resulted in an ORR of $63 \%$ and a DCR of $79 \%$ with a mPFS of 7.9 months ${ }^{61}$.

\section{Immunotherapy}

The emergence of immunotherapy as an effective treatment for many solid tumours has created quite a stir in oncology, though many uncertainties need to be resolved. Checkpoint inhibitors are monoclonal antibodies (mAbs) that specifically target regulatory membrane receptors in either immune or tumour-cells. As tumour cells can exploit these receptors to evade immune system detection, these drugs aim at restoring an efficient immunologic response by blocking, for example, programmed death 1 (PD-1) receptor and its ligands, programmed death ligand-1 (PD-L1) and/or PD-L2. Many molecules directed against this axis have been developed or are currently being studied in NSCLC treatment and can be divided into two main classes: PD-1 inhibitors (nivolumab and pembrolizumab) and PD-L1 directed agents (atezolizumab, durvalumab, and avelumab).

\section{Checkpoint inhibitors in second-line therapy}

Nivolumab has been approved for the second-line treatment of advanced NSCLC following the results of two twin randomized phase III studies, Checkmate 017 and Checkmate 057 , comparing nivolumab with docetaxel in platinum pre-treated advanced squamous and non-squamous NSCLC patients, respectively $^{62,63}$. Nivolumab significantly prolonged OS by approximately 3 months in both studies with less toxicity than chemotherapy, leading to the worldwide approval of this agent.

Pembrolizumab, another anti-PD-1 mAb, was also approved for second-line PD-L1-positive NSCLC treatment following the results of a large phase I trial, which was then confirmed by a phase II/III trial ${ }^{64}$.

The last FDA-approved agent in this setting is atezolizumab, a mAb directed against PD-L1. In a randomized phase II of atezolizumab versus docetaxel for patients with previously treated non-small-cell lung cancer (POPLAR) trial, atezolizumab significantly increased median overall survival (mOS) by 3 months as compared to docetaxel (12.6 versus 9.7 months; HR: 0.73; 95\% CI: 0.53-0-99; p = 0.04) in advanced, previously treated NSCLC 65 . Moreover, an increasing improvement in survival was associated with increasing PD-L1 expression (evaluated in tumour cells and/or tumour-infiltrating immune cells). A subsequent phase III randomized trial (named OAK) ${ }^{66}$ confirmed these findings, leading to drug registration in October 2016. Table 4 reports the results of randomized phase II and III trials in pre-treated advanced NSCLC patients.

\section{Checkpoint inhibitors in first-line therapy}

Following these exciting results in secondline therapy, clinical investigation almost concomitantly moved to the first-line setting. 
TABLE 4. Randomized studies of checkpoint inhibitors in NSCLC second-line therapy

\begin{tabular}{|c|c|c|c|c|c|c|c|}
\hline Drug & Trial & Population & ORR & mOS (months) & $\begin{array}{c}\text { ORR PD-L1 } \\
\text { - negative } \\
\text { (cut-off)/all } \\
\text { patients }\end{array}$ & $\begin{array}{c}\text { ORR PD-L1 - } \\
\text { positive (cut-off) }\end{array}$ & $\begin{array}{l}\text { Treatment- } \\
\text { related } \\
\text { G3-4 AEs }\end{array}$ \\
\hline $\begin{array}{l}\text { Nivolumab } \\
3 \mathrm{mg} / \mathrm{kg} \\
\text { versus } \\
\text { docetaxel } \\
75 \mathrm{mg} / \mathrm{m}^{2}\end{array}$ & $\begin{array}{l}\text { CheckMate017 } \\
\text { Phase III62 }\end{array}$ & $\begin{array}{l}272 \text { platinum } \\
\text { pre-treated } \\
\text { advanced } \\
\text { squamous } \\
\text { NSCLC }\end{array}$ & $\begin{array}{l}20 \text { versus } 9 \% \\
(p=0.008)\end{array}$ & $\begin{array}{c}9.2 \text { versus } 6.0 \\
\text { (HR: } 0.59 ; \\
95 \% \mathrm{Cl}: 0.44-0.79 \\
\mathrm{p}<0.001 \text { ) }\end{array}$ & $\begin{array}{l}17 \% \text { (cut-off } 1 \% \text { ) } \\
15 \% \text { (cut-off } 5 \% \text { ) } \\
16 \% \text { (cut-off } 10 \% \text { ) }\end{array}$ & $\begin{array}{l}17 \% \text { (cut-off } 1 \% \text { ) } \\
21 \% \text { (cut-off } 5 \% \text { ) } \\
19 \% \text { (cut-off } 10 \% \text { ) }\end{array}$ & $\begin{array}{c}9 \text { versus } \\
71 \%\end{array}$ \\
\hline $\begin{array}{l}\text { Nivolumab } \\
3 \mathrm{mg} / \mathrm{kg} \\
\text { versus } \\
\text { docetaxel } \\
75 \mathrm{mg} / \mathrm{m}^{2}\end{array}$ & $\begin{array}{l}\text { CheckMate057 } \\
\text { Phase III63 }\end{array}$ & $\begin{array}{l}582 \text { platinum } \\
\text { pre-treated } \\
\text { advanced } \\
\text { non-squamous } \\
\text { NSCLC }\end{array}$ & $\begin{array}{l}19 \text { versus } 12 \% \\
(p=0.02)\end{array}$ & $\begin{array}{l}12.2 \text { versus } 9.4 \\
\text { (HR: } 0.73 ; \\
96 \% \mathrm{Cl}: 0.59-0.89 \\
p=0.002 \text { ) }\end{array}$ & $\begin{array}{l}9 \% \text { (cut-off } 1 \% \text { ) } \\
10 \% \text { (cut-off } 5 \% \text { ) } \\
11 \% \text { (cut-off } 10 \% \text { ) }\end{array}$ & $\begin{array}{l}31 \% \text { (cut-off } 1 \% \text { ) } \\
36 \% \text { (cut-off } 5 \% \text { ) } \\
37 \% \text { (cut-off } 10 \% \text { ) }\end{array}$ & \\
\hline $\begin{array}{l}\text { Pembrolizumab } \\
2 \mathrm{mg} / \mathrm{kg} \\
\text { versus } \\
\text { pembrolizuma } \\
10 \mathrm{mg} / \mathrm{kg} \\
\text { versus } \\
\text { docetaxel } \\
75 \mathrm{mg} / \mathrm{m}^{2}\end{array}$ & $\begin{array}{c}\text { KEYNOTE-010 } \\
\text { Phase II/III }\end{array}$ & $\begin{array}{l}1034 \text { platinum } \\
\text { pre-treated } \\
\text { PD-L1 -positive } \\
\text { ( } \geq 1 \%) \\
\text { advanced } \\
\text { NSCLC }\end{array}$ & $\begin{array}{l}18 \% \\
(p=0.0005 \\
\text { versus } \mathrm{T}) \\
\text { versus } 18 \% \\
(p=0.0002 \\
\text { versus } \mathrm{T}) \\
\text { versus } 9 \%\end{array}$ & $\begin{array}{c}10.4 \text { (HR: } 0.71 ; \\
95 \% \text { Cl: } 0.58-0.88 ; \\
p=0.0008 \\
\text { versus T) } \\
\text { versus } 12.7 \\
\text { (HR: } 0.61 ; \\
95 \% \text { Cl: } 0.49-0.75, \\
p<0.0001 \\
\text { versus T) } \\
\text { versus } 8.5\end{array}$ & $\begin{array}{c}18 \% \\
18.5 \% \\
9.3 \% \\
\text { (all pts) }\end{array}$ & $\begin{array}{l}30.2 \% \text { (cut-off } 50 \% \text { ) } \\
29.1 \% \text { (cut-off } 50 \% \text { ) } \\
7.9 \% \text { (cut-off } 50 \% \text { ) }\end{array}$ & $\begin{array}{l}13 \text { versus } \\
16 \text { versus } \\
35 \%\end{array}$ \\
\hline $\begin{array}{l}\text { Atezolizumab } \\
1,200 \mathrm{mg} \\
\text { versus } \\
\text { docetaxel } \\
75 \mathrm{mg} / \mathrm{m}^{2}\end{array}$ & $\begin{array}{l}\text { POPLAR } \\
\text { Phase II65 }\end{array}$ & $\begin{array}{l}287 \text { platinum } \\
\text { pre-treated } \\
\text { advanced } \\
\text { NSCLC }\end{array}$ & $\begin{array}{c}14.6 \text { versus } \\
14.7 \%\end{array}$ & $\begin{array}{l}12.6 \text { versus } 9.7 \\
\text { (HR: } 0.73 ; \\
95 \% \mathrm{Cl}: 0.53-0.99 \\
\mathrm{p}=0.04)\end{array}$ & $\begin{array}{l}7.8 \text { versus } 9.8 \% \\
\text { (TC } 0 \text { or IC } 0 \text { ) }\end{array}$ & $\begin{array}{l}18.3 \text { versus } 16.7 \% \\
\text { (TC } 1 / 2 / 3 \text { or IC } 1 / 2 / 3 \text { ) } \\
22.0 \text { versus } 14.5 \% \\
\text { (TC } 2 / 3 \text { or IC } 2 / 3 \text { ) } \\
37.5 \text { versus } 13.0 \% \\
\text { (TC } 3 \text { or IC } 3 \text { ) }\end{array}$ & $\begin{array}{c}11 \text { versus } \\
39 \%\end{array}$ \\
\hline $\begin{array}{l}\text { Atezolizumab } \\
1,200 \mathrm{mg} \\
\text { versus } \\
\text { docetaxel } \\
75 \mathrm{mg} / \mathrm{m}^{2}\end{array}$ & OAK Phase $\|^{66}$ & $\begin{array}{l}850 \text { platinum } \\
\text { pre-treated } \\
\text { advanced } \\
\text { NSCLC (1 or } \\
2 \text { previous } \\
\text { lines) }\end{array}$ & $\begin{array}{l}14 \text { versus } \\
13 \%\end{array}$ & $\begin{array}{c}13.8 \text { versus } 9.6 \\
\text { (HR: } 0.73 ; \\
95 \% \mathrm{Cl}: 0.62-0.87 \\
\mathrm{p}=0.0003)\end{array}$ & 8 versus $11 \%$ & $\begin{array}{l}18 \%(\mathrm{TC} 1 / 2 / 3 \text { or IC } \\
1 / 2 / 3) \text { versus } 16 \% \\
(\mathrm{TC} 1 / 2 / 3 \text { or IC } 1 / 2 / 3)\end{array}$ & $\begin{array}{l}37 \text { versus } \\
54 \%\end{array}$ \\
\hline
\end{tabular}

AEs: adverse events; Cl: confidence interval; HR: hazard ratio; IC: immune cells; mOS: median overall survival; NSCLC: non small cell lung cancer; ORR: objective response rate; PD-L1: programmed death - ligand 1; T: docetaxel; TC: tumor cells; KEYNOTE-010 Phase II and III: advanced non small cell lung cancer; POPLAR Phase II: previously treated non small cell lung cancer; OAK Phase III: previously treated non small cell lung cancer.

In 2016, the results of two phase III randomized trials in this setting were reported. In the CheckMate 026 study, nivolumab failed to improve PFS as compared to platinum-based doublet chemotherapy in untreated NSCLC patients whose tumours had a PD-L1 expression of $5 \%$ or greater ${ }^{67}$.

Conversely, pembrolizumab significantly increased mPFS by 4 months (10.3 versus 6.0 months; HR: 0.50; 95\% CI: 0.37-0.68; p < 0.001) as compared to platinum-doublet chemotherapy in previously untreated NSCLC with a PD-L1 expression of at least 50\% according to the results of a randomized phase III trial. Moreover, the estimated overall survival (OS) rate was $80.2 \%$ at 6 months with pemborlizumab compared to $72.4 \%$ for chemotherapy (HR: 0.60; 95\% CI: 0.41-0.89; $\mathrm{p}=0.005)$, the latter treatment being associated with more AEs of 
any grade ${ }^{68}$. Given these results, in October 2016, pembrolizumab was approved by the U.S. FDA as the first-line treatment of advanced NSCLC with high PD-L1 expression (at least 50\%) and without EGFR activating mutations or ALK rearrangements ${ }^{69}$. However, it should be noted that, considering the strict eligibility criteria of the first-line pembrolizumab study, the proportion of NSCLC patients who are potential candidates for front-line pembrolizumab is estimated to be in the range of 10 $15 \%$ of all patients with advanced NSCLC.

Besides PD-1 checkpoint inhibitors, PD-L1 directed agents (avelumab and atezolizumab) are also being explored in front-line therapy but, as of today, only data from phase I and II studies have been reported ${ }^{70,71}$.

\section{Toxicity}

Due to their specific mechanism of action, immune checkpoint inhibitors are characterized by a new spectrum of AEs, many of them with an immune-related mechanism. They include damage to endocrine glands (thyroiditis, adrenalitis, hypophysitis), skin (rash), gastrointestinal tract (with diarrhea and colitis), lungs (pneumonitis), liver (hepatitis), and kidneys (nephritis) ${ }^{72}$. Even if these toxicities are usually mild (especially when compared to those seen with chemotherapy), they could be subtle in their presentation and become life-threatening when not promptly recognized and treated ${ }^{73}$.

\section{Early data from combination therapies}

In order to further extend these results, another active field of investigation is that of combination strategies, which can be divided into two main approaches: combinations of different immune checkpoint inhibitors and combinations of chemotherapy and checkpoint inhibitors.

The association of cytotoxic T-lymphocyte-associated protein 4 (CTLA-4) and PD-1 checkpoint inhibitors seems to enhance ORR in advanced NSCLC patients, especially in those with a low PD-L1 expression on tumour cells according to the results of two cohorts of the phase I study CheckMate $012^{74}$. However, a higher rate of AEs was observed in the combination arms, even though they were mostly manageable.

The combination of carboplatin plus pemetrexed with or without pembrolizumab as a first-line treatment for advanced non-squamous NSCLC was evaluated in the cohort of a randomized phase II study (KEYNOTE-021) ${ }^{75}$. A $26 \%$ difference in RR was observed, favouring the experimental arm (55 versus 29\%; 95\% CI: 9-42\%; p = 0.0016), and a randomized phase III trial is currently ongoing in this setting [NCT02578680]. Other combinations, such as chemotherapy doublets with a PD-L1 inhibitor with or without an anti-CTLA- $4 \mathrm{mAb}$, are currently under investigation with interesting preliminary results ${ }^{76}$.

\section{RADIOTHERAPY: FOCUS ON STEREOTACTIC BODY RADIOTHERAPY (SBRT)}

SBRT has mainly been adopted in patients with stage I-II peripheral inoperable NSCLC. While three phase III randomized trials comparing surgery to SBRT have been started, all 
of them closed early due to poor accrual. A subsequent pooled analysis of data from 58 patients from two of these studies demonstrated an improved 3 years OS with SBRT as compared to lobectomy ( 95 versus $79 \%, p=0.037$ ), while no differences in recurrence-free survival were observed ${ }^{77}$.

A small randomized trial compared SBRT (66 Gy in $<3$ fractions) and conventional fractionated 3D radiotherapy (70 Gy in 7 weeks) in stage I medically inoperable NSCLC patients. No differences in OS and PFS were observed, though patients treated with SBRT reported better quality of life and less toxicity $^{78}$.

\section{CONCLUSIONS}

The first step in lung cancer control is to identify and address the growing number of known risk factors, especially air pollution with fine particulate matter $\left(\mathrm{PM}_{2.5}\right)$. In addition, the development of sustainable and efficient lung cancer screening programmes could play a crucial role in reducing lung cancer mortality. Improvements in CT nodule volumetry and new bronchoscopy approaches are novel instruments to reduce uncertainty and better determine candidates for surgery. Patient and centre selection for lung cancer surgery are crucial variables for getting the best candidates. New selection mortality scores are now available, though patient-centred outcomes are increasingly discussed and are being considered for implementation in the near future. With its excellent local control rates and low morbidity, SBRT is now considered to be a curative treatment option for patients with early stage NSCLC, especially those considered medically inoperable. Ongoing phase III trials will hopefully strengthen its role in larger populations.

The continuous identification of new genomically-defined lung cancer subpopulations allowed for the design of multi-arm clinical trials that simultaneously test multiple drugs or combinations in different molecularly selected patients. These "master protocols" offer the possibility of giving to each subpopulation of patients a targeted treatment, optimizing the clinical development of personalized therapies even in small groups of patients.

Immune checkpoint inhibitors are rapidly changing our clinical practice in advanced disease management and many efforts are directed towards the identification of reliable factors for patient selection. In this context, the IASLC, together with diagnostic companies and pharmaceutical industries, is currently involved in comparing, optimizing and homogenizing different PD-L1 immunohistochemical diagnostic assays. Beside PD-L1 evaluation, other potential predictive tools such as the analysis of tumour nonsynonymous mutation burden 79,80 as well as neo-epitope load $^{81}$, are under investigation. In the near future, additional areas of clinical investigation for immune checkpoint inhibitors will focus on the duration of treatment, as well as on the sequencing of immunotherapy, chemotherapy and targeted therapies. Cost-effectiveness studies and long-term sustainability for health care systems are additional questions to be addressed. Last but not least, one of the biggest efforts over the coming years will be to educate the medical community, including nurses, patients and caregivers, to promptly recognize and treat immune AEs. 


\section{ACKNOWLEDGEMENTS}

To David Bridgewater (anglocatalan@yahoo. es) for writing assistance and language help.

\author{
Support: Project 20133510 Fundació La Ma- \\ rató TV3
}

Disclaimers: None

\section{CONFLICT OF INTEREST}

Dr. Giorgio Vittorio Scagliotti reports personal fees from Eli Lilly, personal fees from Roche, personal fees from Pfizer, personal fees from AstraZeneca, personal fees from MSD, outside the submitted work; Dr. Paolo Bironzo reports personal fees from BMS, outside the submitted work; Dr. Antoni Rosell has nothing to disclose.

\section{REFERENCES}

1. Tanner NT, Kanodra NM, Gebregziabher M et al. The Association between Smoking Abstinence and Mortality in the National Lung Screening Trial. Am J Respir Crit Care Med. 2016;193(5):534-41.

2. Raaschou-Nielsen O, Andersen ZJ, Beelen R et al. Air pollution and lung cancer incidence in 17 European cohorts: prospective analyses from the European Study of Cohorts for Air Pollution Effects (ESCAPE). Lancet Oncol. 2013;14(9):813-22.

3. Guo Y, Zeng H, Zheng R et al. The burden of lung cancer mortality attributable to fine particles in China. Sci Total Environ. 2017;579:1460-6.

4. Moyer VA. Screening for lung cancer: U.S. Preventive Services Task Force recommendation statement. Ann Intern Med. 2014;160(5):330-8.

5. Heuvelmans MA, Oudkerk M, de Bock GH et al. Optimisation of volume-doubling time cutoff for fast-growing lung nodules in CT lung cancer screening reduces false-positive referrals. Eur Radiol. 2013;23(7):1836-45.

6. Walter JE, Heuvelmans MA, de Jong PA et al. Occurrence and lung cancer probability of new solid nodules at incidence screening with low-dose CT: analysis of data from the randomised, controlled NELSON trial. The Lancet Oncology. 2016;17(7):907-16

7. Bronte G, Rolfo C. Semi-automated volumetric analysis in the NELSON trial for lung cancer screening: is there room for diagnostic experience yet? J Thorac Dis. 2016;8(11):E1490-E2.

8. Kovalchik SA, Tammemagi M, Berg CD et al. Targeting of low-dose CT screening according to the risk of lung-cancer death. N Engl J Med. 2013; 369(3):245-54.

9. Katki HA, Kovalchik SA, Berg CD, Cheung LC, Chaturvedi AK. Development and Validation of Risk Models to Select Ever-Smokers for CT Lung Cancer Screening. JAMA. 2016;315(21):2300-11.
10. Montani F, Marzi MJ, Dezi F et al. miR-Test: a blood test for lung cancer early detection. J Natl Cancer Inst. 2015;107(6):djv063.

11. Zhu L, Liu J, Ma S et al. Long Noncoding RNA MALAT-1 Can Predict Metastasis and a Poor Prognosis: a Meta-Analysis. Pathol Oncol Res. 2015; 21(4):1259-64.

12. Chen $\mathrm{S}, \mathrm{Wu} \mathrm{H}, \mathrm{Lv} \mathrm{N}$ et al. LncRNA CCAT2 predicts poor prognosis and regulates growth and metastasis in small cell lung cancer. Biomed Pharmacother. 2016;82:583-8.

13. Kunz M, Wolf B, Schulze $H$ et al. Non-Coding RNAs in Lung Cancer: Contribution of Bioinformatics Analysis to the Development of Non-Invasive Diagnostic Tools. Genes (Basel). 2016;8(1).

14. Bharmal A, Crosskill A, Lam S et al. Controlled settings for lung cancer screening: why do they matter? Considerations for referring clinicians. Curr Oncol. 2016;23(6):371-3.

15. Harzheim D, Sterman D, Shah PL et al. Bronchoscopic Transparenchymal Nodule Access: Feasibility and Safety in an Endoscopic Unit. Respiration. 2016;91(4):302-6.

16. Crombag LM, Annema JT. Left Adrenal Gland Analysis in Lung Cancer Patients Using the Endobronchial Ultrasound Scope: A Feasibility Trial. Respiration. 2016;91(3):235-40.

17. Kazakov J, Hegde P, Tahiri M et al. Endobronchial and Endoscopic Ultrasound-Guided Transvascular Biopsy of Mediastinal, Hilar, and Lung Lesions. Ann Thorac Surg. 2017;103(3):951-5.

18. Henne E, Ferguson JS, Mest R et al.. Thermal Vapor Ablation for Lung Lesions in a Porcine Model. Respiration. 2015;90(2):146-54.

19. Stratakos G, Gerovasili V, Dimitropoulos C et al. Survival and Quality of Life Benefit after Endoscopic Management of Malignant Central Airway Obstruction. J Cancer. 2016;7(7):794-802.

20. Detterbeck FC, Boffa DJ, Kim AW et al. The 8th Edition Lung Cancer Stage Classification. Chest. 2016.

21. Brunelli A, Salati M, Rocco G et al. European risk models for morbidity (EuroLung1) and mortality (EuroLung2) to predict outcome following anatomic lung resections: an analysis from the European Society of Thoracic Surgeons database †, f. Eur J Cardiothorac Surg. 2017;51(3):490-7.

22. Sebio Garcia R, Yanez Brage MI, Gimenez Moolhuyzen E et al. Functional and postoperative outcomes after preoperative exercise training in patients with lung cancer: a systematic review and meta-analysis. Interact Cardiovasc Thorac Surg. 2016;23(3):486-97.

23. Moller H, Riaz SP, Holmberg L et al. High lung cancer surgical procedure volume is associated with shorter length of stay and lower risks of re-admission and death: National cohort analysis in England. Eur J Cancer. 2016;64:32-43.

24. Samson P, Crabtree T, Broderick S et al. Quality Measures in Clinical Stage I Non-Small Cell Lung Cancer: Improved Performance Is Associated With Improved Survival. Ann Thorac Surg. 2017;103(1):303-11.

25. Attaar A, Winger DG, Luketich JD et al. A clinical prediction model for prolonged air leak after pulmonary resection. J Thorac Cardiovasc Surg. 2017;153(3)690-9.

26. Mak KS, van Bommel AC, Stowell C et al. Defining a standard set of patient-centred outcomes for lung cancer. Eur Respir J. 2016;48(3):852-60.

27. Louie BE, Wilson JL, Kim S et al. Comparison of Video-Assisted Thoracoscopic Surgery and Robotic Approaches for Clinical Stage I and Stage II Non-Small Cell Lung Cancer Using The Society of Thoracic Surgeons Database. Ann Thorac Surg. 2016;102(3):917-24.

28. Kelly K, Altorki NK, Eberhardt WE et al. Adjuvant Erlotinib Versus Placebo in Patients With Stage IB-IIIA Non-Small-Cell Lung Cancer (RADIANT): A Randomized, Double-Blind, Phase III Trial. J Clin Oncol. 2015;33(34): 4007-14.

29. Vansteenkiste JF, Cho BC, Vanakesa T et al. Efficacy of the MAGE-A3 cancer immunotherapeutic as adjuvant therapy in patients with resected MAGE-A3-positive non-small-cell lung cancer (MAGRIT): a randomised, double-blind, placebo-controlled, phase 3 trial. Lancet Oncol. 2016;17(6): 822-35.

30. Senan S, Brade A, Wang LH et al. PROCLAIM: Randomized Phase III Trial of Pemetrexed-Cisplatin or Etoposide-Cisplatin Plus Thoracic Radiation Therapy Followed by Consolidation Chemotherapy in Locally Advanced 
Nonsquamous Non-Small-Cell Lung Cancer. J Clin Oncol. 2016;34(9): 953-62.

31. Isla D, De Las Peñas RR, Mars R et al. MA06.09 Efficacy RENO study results of oral vinorelbine or etoposide with cisplatin \& chemo-radiation in stage III NSCLC. SLCG 10/02. J Thorac Oncol. 2017;12(1)S373-4.

32. Forde PM, Smith K, Chaft JE et al. LBA41_PR - Neoadjuvant anti-PD1, nivolumab, in early stage resectable non-small-cell lung cancer. Ann Oncol. 2016;27(6):1-36

33. de Mello RA, Velosa AF, Esrom Catarina P et al. Potential role of immunotherapy in advanced non-small-cell lung cancer. Onco Targets Ther. 2016;10: 21-30.

34. Park K, Tan EH, O'Byrne K et al. Afatinib versus gefitinib as first-line treatment of patients with EGFR mutation-positive non-small-cell lung cancer (LUX-Lung 7): a phase 2B, open-label, randomised controlled trial. Lancet Oncol. 2016;17(5):577-89.

35. Paz-Ares L, Tan EH, Zhang L et al. LBA43 Afatinib (A) vs gefitinib (G) in patients (pts) with EGFR mutation-positive (EGFRm+) non-small-cell lung cancer (NSCLC): overall survival (OS) data from the phase IIb trial LUXLung 7 (LL7) Ann Oncol. 2016;27(suppl 6):vi552-vi887.

36. Mok TS, Wu YL, Ahn MJ et al. Osimertinib or Platinum-Pemetrexed in EGFR T790M-Positive Lung Cancer. N Engl J Med. 2017;376:629-40.

37. Wu YL, Jenkins S, Ramalingam S et al. MA08.03 Osimertinib vs platinum-pemetrexed for T790M-mutation positive advanced NSCLC (AURA3): plasma ctDNA analysis J Thorac Oncol. 2017;12(Suppl 1):S195.

38. Oxnard GR, Thress KS, Alden RS et al. Association Between Plasma Genotyping and Outcomes of Treatment With Osimertinib (AZD9291) in Advanced Non-Small-Cell Lung Cancer. J Clin Oncol. 2016;34(28):3375-82.

39. Reckamp KL, Melnikova VO, Karlovich C et al. A Highly Sensitive and Quantitative Test Platform for Detection of NSCLC EGFR Mutations in Urine and Plasma. J Thorac Oncol. 2016;11(10):1690-700.

40. Ou SH, Ahn JS, De Petris L et al. Alectinib in Crizotinib-Refractory ALK-Rearranged Non-Small-Cell Lung Cancer: A Phase II Global Study. J Clin Oncol. 2016;34(7):661-8.

41. Nokihara $H$, Hida $T$, Kondo $M$ et al. Alectinib (ALC) versus crizotinib (CRZ) in ALK-inhibitor naive ALK-positive non-small cell lung cancer (ALK+ NSCLC): primary results from the J-ALEX study. J Clin Oncol. 2016; 34(suppl): abstr 9008.

42. de Castro GJ, Tan DS, Crinò L et al. PL03.07 First-line ceritinib versus chemotherapy in patients with ALK-rearranged (ALK+) NSCLC: a randomized, phase 3 study (ASCEND-4). J Thorac Oncol. 2017; Volume 12(Suppl 1):S4.

43. Scagliotti G, Kim TM, Crinò L et al. LBA42_PR Ceritinib vs chemotherapy (CT) in patients (pts) with advanced anaplastic lymphoma kinase (ALK)-rearranged $(\mathrm{ALK}+)$ non-small cell lung cancer (NSCLC) previously treated with CT and crizotinib (CRZ): results from the confirmatory phase 3 ASCEND-5 study. Ann Oncol. 2016;27(suppl 6):vi552-vi87.

44. Kim DW, Tiseo M, Ahn MJ et al. Brigatinib (BRG) in patients (pts) with crizotinib (CRZ)-refractory ALK+ non-small cell lung cancer (NSCLC): first report of efficacy and safety from a pivotal randomized phase (ph) 2 trial (ALTA). J Clin Oncol. 2016;34(suppl):abstr 9007.

45. Solomon BJ, Bauer TM, Felip E et al. Safety and efficacy of lorlatinib (PF06463922) from the dose-escalation component of a study in patients with advanced ALK+ and ROS1+ non-small cell lung cancer (NSCLC). J Clin Oncol. 2016;34(suppl):abstr 9009.

46. Gainor JF, Dardaei L, Yoda S et al. Molecular Mechanisms of Resistance to First- and Second-Generation ALK Inhibitors in ALK-Rearranged Lung Cancer. Cancer Discov. 2016;6(10):1118-33.

47. Wang Y, Tian PW, Wang WY et al. Noninvasive genotyping and monitoring of anaplastic lymphoma kinase (ALK) rearranged non-small cell lung cancer by capture-based next-generation sequencing. Oncotarget. 2016;7(40): 65208-17.

48. FDA expands use of Xalkori to treat rare form of advanced non-small cell lung cancer [Internet]. 2016; March 11, 2016 [cited Januray 2, 2017]. Available from: http://www.fda.gov/NewsEvents/Newsroom/PressAnnouncements/ ucm 490329.htm
49. Shaw AT, Ou SH, Bang YJ et al. Crizotinib in ROS1-rearranged non-smallcell lung cancer. N Engl J Med. 2014;371(21):1963-71.

50. Park SJ, More S, Murtuza A, Woodward BD, Husain H. New Targets in NonSmall Cell Lung Cancer. Hematol Oncol Clin North Am. 2017;31(1):113-29.

51. Takeuchi K, Soda M, Togashi Y et al. RET, ROS1 and ALK fusions in lung cancer. Nat Med. 2012;18(3):378-81.

52. Lee SH LJ, Ahn MJ et al. A phase II study of vandetanib in patients with non-small cell lung cancer harboring RET rearrangement. J Clin Oncol. 2016;34(suppl):abstr 9013.

53. Gautschi O WJ, Milia J et al. Targeting RET in patients with RET-rearranged lung cancers: results from a global registry. J Clin Oncol. 2016;34(suppl):abstr 9014.

54. Rolfo C, Ruiz R, Giovannetti E et al. Entrectinib: a potent new TRK, ROS1, and ALK inhibitor. Expert Opin Investig Drugs. 2015;24(11):1493-500.

55. Onozato R, Kosaka T, Kuwano $\mathrm{H}$ et al. Activation of MET by gene amplification or by splice mutations deleting the juxtamembrane domain in primary resected lung cancers. J Thorac Oncol. 2009;4(1):5-11.

56. Awad MM, Oxnard GR, Jackman DM et al. MET Exon 14 Mutations in Non-Small-Cell Lung Cancer Are Associated With Advanced Age and Stage-Dependent MET Genomic Amplification and c-Met Overexpression. J Clin Oncol. 2016;34(7):721-30.

57. Wu YL, Kim DW, Felip E et al. Phase (Ph) II safety and efficacy results of a single-arm ph ib/II study of capmatinib (INC280) + gefitinib in patients (pts) with EGFR-mutated (mut), cMET positive (MET+) non-small cell lung cancer (NSCLC). J Clin Oncol. 2016;34(suppl):abstr 9020.

58. Jänne PA, van den Heuvel M, Barlesi F et al. Selumetinib in combination with docetaxel as second-line treatment for patients with KRAS-mutant advanced NSCLC: Results from the phase III SELECT-1 trial. Ann Oncol. 2016;27(suppl_6):LBA47_PR-LBA_PR.

59. Planchard D, Kim TM, Mazieres J et al. Dabrafenib in patients with BRAF(V600E)-positive advanced non-small-cell lung cancer: a single-arm, multicentre, open-label, phase 2 trial. Lancet Oncol. 2016;17(5):642-50.

60. Hyman DM, Puzanov I, Subbiah V et al. Vemurafenib in Multiple Nonmelanoma Cancers with BRAF V600 Mutations. N Engl J Med. 2015;373(8):726-36.

61. Planchard D, Besse B, Groen HJ et al. Dabrafenib plus trametinib in patients with previously treated BRAF(V600E)-mutant metastatic non-small cell lung cancer: an open-label, multicentre phase 2 trial. Lancet Oncol. 2016; 17(7):984-93.

62. Brahmer J, Reckamp KL, Baas P et al. Nivolumab versus Docetaxel in Advanced Squamous-Cell Non-Small-Cell Lung Cancer. N Engl J Med. 2015; 373(2):123-35.

63. Borghaei H, Paz-Ares L, Horn L et al. Nivolumab versus Docetaxel in Advanced Nonsquamous Non-Small-Cell Lung Cancer. N Engl J Med. 2015; 373(17):1627-39.

64. Herbst RS, Baas P, Kim DW et al. Pembrolizumab versus docetaxel for previously treated, PD-L1-positive, advanced non-small-cell lung cancer (KEYNOTE-010): a randomised controlled trial. Lancet. 2016;387(10027):1540-50.

65. Fehrenbacher L, Spira A, Ballinger M et al. Atezolizumab versus docetaxe for patients with previously treated non-small-cell lung cancer (POPLAR): a multicentre, open-label, phase 2 randomised controlled trial. Lancet. 2016; 387(10030):1837-46

66. Rittmeyer A, Barlesi F, Waterkamp D et al. Atezolizumab versus docetaxel in patients with previously treated non-small-cell lung cancer (OAK): phase 3, open-label, multicentre randomised controlled trial. Lancet. 2017; 389(10066):255-65.

67. Socinski M, Creelan B, Horn L et al. CheckMate 026: a phase 3 trial of nivolumab vs investigator's choice (IC) of platinum-based doublet chemotherapy (PT-DC) as first-line treatment for stage IV/recurrent programmed death ligand-1 (PD-L1) positive NSCLC. Ann Oncol. 2016;2016(27 (suppl 6)):vi588.

68. Reck M, Rodriguez-Abreu D, Robinson AG et al. Pembrolizumab versus Chemotherapy for PD-L1-Positive Non-Small-Cell Lung Cancer. N Engl J Med. 2016; 375(19):1823-33.

69. FDA Approves Merck's KEYTRUDA® (pembrolizumab) in Metastatic NSCLC for First-Line Treatment of Patients Whose Tumors Have High PD-L1 Expression (Tumor Proportion Score [TPS] of 50 Percent or More) With No EGFR 
or ALK Genomic Tumor Aberrations [Internet]. 2016. Available from: http://www.mercknewsroom.com/news-release/prescription-medicinenews/fda-approves-mercks-keytruda-pembrolizumab-metastatic-nsclc-

70. Jerusalem G, Chen F, Spigel D et al. OA03.03 JAVELIN solid tumor: safety and clinical activity of avelumab (anti-PD-L1) as fisrt-line treatment in patients with advanced NSCLC. J Thorac Oncol. 2017;12(suppl 1):S130.

71. Garassino M, Rizvi N, Besse B et al. OA03.02 Atezolizumab as 1L therapy for advanced NSCLC in PD-L1-selected patients: updated ORR,PFS and OS data from the BIRCH study. J Thorac Oncol. 2017;12(suppl 1):S130.

72. Michot JM, Bigenwald C, Champiat $S$ et al. Immune-related adverse events with immune checkpoint blockade: a comprehensive review. Eur J Cancer. 2016;54:139-48.

73. Champiat S, Lambotte O, Barreau E et al. Management of immune checkpoint blockade dysimmune toxicities: a collaborative position paper. Ann Oncol. 2016;27(4):559-74.

74. Hellmann MD, Rizvi NA, Goldman JW et al. Nivolumab plus ipilimumab as first-line treatment for advanced non-small-cell lung cancer (CheckMate 012): results of an open-label, phase 1, multicohort study. Lancet Oncol. 2017; 18(1):31-41.

75. Langer CJ, Gadgeel SM, Borghaei H et al. Carboplatin and pemetrexed with or without pembrolizumab for advanced, non-squamous non-small-cell lung cancer: a randomised, phase 2 cohort of the open-label KEYNOTE-021 study. Lancet Oncol. 2016;17(11):1497-508.

76. Juergens R, Hao D, Laurie S et al. MA09.03 Cisplatin/Pemetrexed + Durvalumab +/- Tremelimumab in pts with advanced non-squamous
NSCLC: a CCTG phase IB study - IND.226 J Thorac Oncol. 2017;12(suppl 1): S199.

77. Chang JY, Senan S, Paul MA et al. Stereotactic ablative radiotherapy versus lobectomy for operable stage I non-small-cell lung cancer: a pooled analysis of two randomised trials. Lancet Oncol. 2015;16(6):630-7.

78. Nyman J HA, Lund JA et al. SPACE -A randomized study of SBRT vs conventional fractionated radiotherapy in medically inoperable NSCLC. Radiother Oncol. 2016;2016(121):1-8.

79. Rizvi NA, Hellmann MD, Snyder A et al. Cancer immunology. Mutational landscape determines sensitivity to PD-1 blockade in non-small cell lung cancer. Science. 2015;348(6230):124-8.

80. Mahadevan N, Adeni A, Hammerman P et al. MA15.02 Non-synonimous mutation burden in lung carcinoma is associated with durable clinical response to immune checkpoint blockade. J Thorac Oncol. 2017;12(suppl 1):S220.

81. Campbell JD, Alexandrov A, Kim J et al. Distinct patterns of somatic genome alterations in lung adenocarcinomas and squamous cell carcinomas. Nat Genet. 2016;48(6):607-16.

82. Korevaar DA, Crombag LM, Cohen JF, Spijker R, Bossuyt PM, Annema JT Added value of combined endobronchial and oesophageal endosonography for mediastinal nodal staging in lung cancer: a systematic review and meta-analysis. Lancet Respir Med. 2016 Dec;4(12):960-8. doi: 10.1016/ S2213-2600(16)30317-4.

83. Bernardin L, O'Flynn EAM, deSouza NM. Functional imaging biomarkers for assessing response to treatment in liver and lung metastases. Cancer Imaging. 2013;13(4):482-94 